\title{
Rotational intraperitoneal pressurized aerosol chemotherapy in a porcine model
}

\author{
Jaehee Mun", Soo Jin Park", Hee Seung Kim \\ Department of Obstetrics and Gynecology, Seoul National University College of Medicine, Seoul, Korea \\ Contributions: (I) Conception and design: SJ Park, HS Kim; (II) Administrative support: HS Kim; (III) Provision of study materials or patients: SJ \\ Park, HS Kim; (IV) Collection and assembly of data: J Mun, HS Kim; (V) Data analysis and interpretation: J Mun, HS Kim; (VI) Manuscript writing \\ and revision: All Authors; (VIII) Final approval of manuscript: All Authors. \\ \#These authors contributed equally to this work. \\ Correspondence to: Hee Seung Kim, MD, PhD. Department of Obstetrics and Gynecology, Seoul National University College of Medicine, 101 \\ Daehak-Ro Jongno-Gu, Seoul 110-744, Korea. Email: bboddi0311@gmail.com.
}

\begin{abstract}
Peritoneal carcinomatosis (PC) commonly represent drug resistance to intravenous (IV) chemotherapy in advanced or recurrent disease of solid tumors. For improving the prognosis of PC, intraperitoneal (IP) chemotherapy has been introduced in the clinical setting, and phase III trials proved the superiority of IP chemotherapy to IV chemotherapy, in particular, in advanced ovarian cancer. However, increased toxicities by IP chemotherapy lead to reduced cycles of chemotherapy, which does not guarantee its effectiveness. Moreover, hyperthermic IP chemotherapy after cytoreductive surgery also showed improved survival compared to IV chemotherapy in advanced ovarian cancer. Nevertheless, limited distribution and diffusion of drugs, and grade 3 or 4 renal and hepatic toxicity of $20 \%$ preclude the expansion of its application. On the other hand, pressurized intraperitoneal aerosol chemotherapy (PIPAC) is known to show the effect by delivering drugs to the parietal and visceral peritoneum in the form of aerosol under the abdominal pressure of $12 \mathrm{mmHg}$ induced by laparoscopic system. Although low dose equivalent to about $1 \%$ dose of resistant drugs for IV chemotherapy and normothermia are used in PIPAC, it may improve tumor response and quality of life by repetitive application of PIPAC due to the increased distribution and penetration depth of drugs. However, the heterogeneous distribution of drugs is still the major limitation of PIPAC because the nozzle is placed at the possible outlying position to the tumor-bearing tissues during laparoscopic surgery. Therefore, we developed a novel prototype for PIPAC, rotational intraperitoneal pressurized aerosol chemotherapy (RIPAC) system because rotation of the nozzle and change of spray direction can contribute to homogenous distribution of drugs, and compared the distribution of drugs between PIPAC and RIPAC in a porcine model mimicking human body. As a result, RIPAC was more effective than PIPAC in terms of the distribution of drugs into the visceral and parietal peritoneum.
\end{abstract}

Keywords: Rotational; pressurized; intraperitoneal (IP); aerosol; chemotherapy

Submitted Mar 02, 2020. Accepted for publication Jul 15, 2020.

doi: $10.21037 /$ gs-2019-ursoc-11

View this article at: http://dx.doi.org/10.21037/gs-2019-ursoc-11

\section{Introduction}

Peritoneal carcinomatosis (PC) occurs commonly in advanced or recurrent disease of solid tumors. More than $80 \%$ of patients with advanced ovarian cancer and $10-60 \%$ of those with recurrent colorectal cancer show PC $(1,2)$.
However, PC is one of the important factors related to the failure of treatment in patients with ovarian and colorectal cancers, who usually show poor survival of less than 20 months (3).

The current strategy using intravenous (IV) chemotherapy is limited to improve the prognosis of PC 


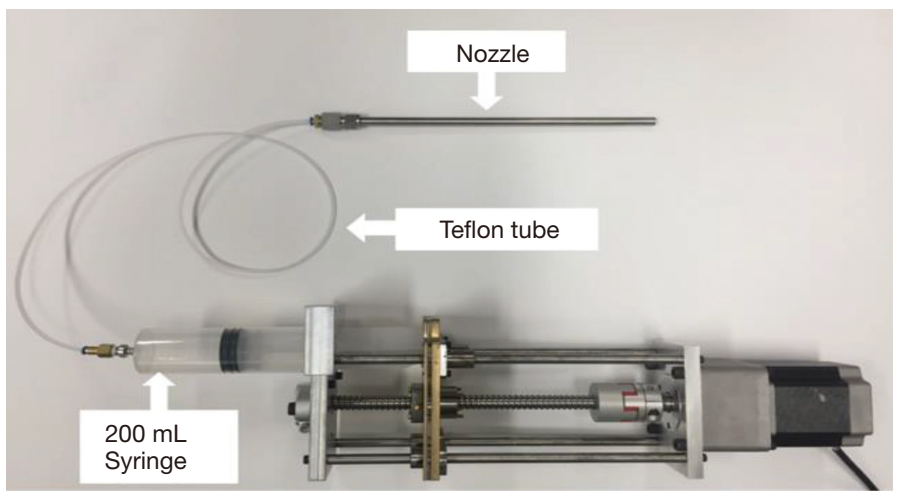

Figure 1 Novel prototype for PIPAC. PIPAC, pressurized intraperitoneal aerosol chemotherapy.

because it develops as a result of multi-drug resistance (4). Thus, intraperitoneal (IP) chemotherapy has been suggested to increased survival, in particular, in patients with advanced ovarian cancer in phase III trials $(5,6)$. However, increased toxicities by IP chemotherapy lead to reduced cycles of chemotherapy, which can contribute to the lack of superiority compared to IV chemotherapy (7).

For increasing the effect of IP chemotherapy, hyperthermic intraperitoneal chemotherapy (HIPEC) after cytoreductive surgery has been introduced, which shows the drug effect under hyperthermia of $41-43{ }^{\circ} \mathrm{C}$ by destroying the microtubule system, inducing protein degeneration, and inhibiting angiogenesis in tumors $(8,9)$. Although HIPEC has been shown to improve survival compared to IV chemotherapy in advanced ovarian cancer (10), limited distribution and diffusion of drugs, and grade 3 or 4 renal and hepatic toxicity of $20 \%$ preclude the expansion of its application in the clinical setting (11).

On the other hand, pressurized intraperitoneal aerosol chemotherapy (PIPAC) demonstrates the effect by delivering drugs to the parietal and visceral peritoneum in the form of aerosol under the abdominal pressure of $12 \mathrm{mmHg}$ induced by the laparoscopic system (12). Low dose equivalent to about $1 \%$ dose of drugs for IV chemotherapy and normothermia in PIPAC may decrease treatment-related toxicity compared to $\operatorname{HIPEC}(13,14)$. In spite of the use of resistant drugs, treatment response, and quality of life are improved by repetitive application of PIPAC due to the increased distribution and penetration depth of drugs $(15,16)$.

Nevertheless, heterogeneous distribution of drugs is the major limitation of PIPAC because the nozzle is placed at the possible outlying position to the tumor-bearing tissues, which may be related to the reduced penetration depth. Thus, rotation of the nozzle and change of spray direction can be considered to overcome this limitation (17). Therefore, we developed a novel prototype for PIPAC, and will compare the distribution of drugs between PIPAC and rotational intraperitoneal pressurized aerosol chemotherapy (RIPAC) system in a porcine model mimicking human body (Video 1).

\section{Operative techniques}

\section{Prototype development}

For delivering drugs in the form of aerosol, we made a novel prototype for PIPAC (18).

The novel prototype for PIPAC sprays approximately $30 \mu \mathrm{m}$ drug droplets at a flow rate of $30 \mathrm{~mL} / \mathrm{min}$ with 7 bar pressures. The average diameter of sprayed region with concentrated dye was approximately $18.5 \mathrm{~cm}$, which comparable to that of the current system of PIPAC (Figure 1).

\section{Preparation}

We used two female swine, which weighed from 40 to $50 \mathrm{~kg}$. For evaluating the distribution of drugs, we used $1 \%$ methylene blue of $150 \mathrm{~mL}$ made by dilution of $1.5 \%$ methylene blue of $100 \mathrm{~mL}$ (Sigma-Aldrich, Seoul, South Korea) into $0.9 \% \mathrm{NaCl}$ of $0.9 \%$. Capnoperitoneum was made by $\mathrm{CO}_{2}$ insufflation via a Veress needle. We inserted three 12-mm bladeless trocars (Transport ${ }^{\circledR}$; Dalim Corp., Seoul, South Korea) along the midline of the abdomen for IP chemotherapy, which was used as passages for insertion of the nebulizer, laparoscopic camera, and devices. 


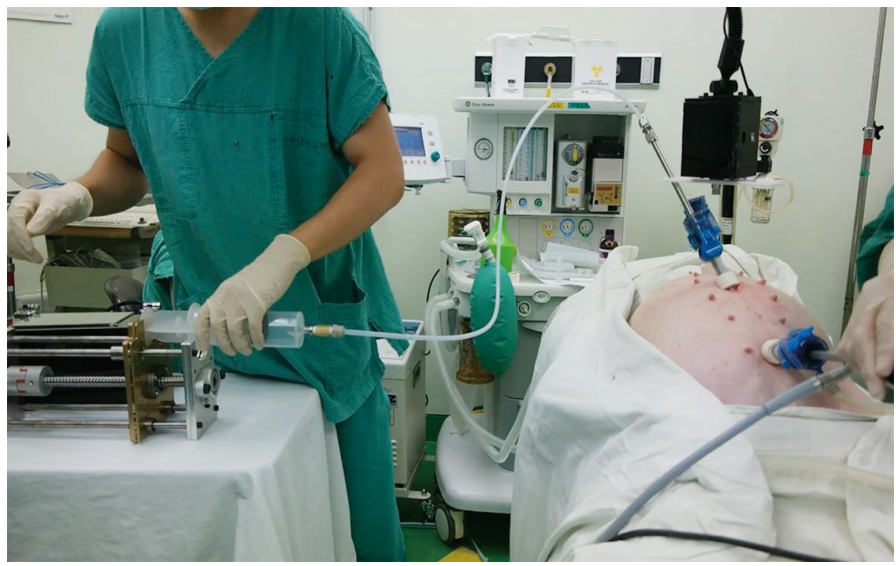

Figure 2 Setting of RIPAC in swine. RIPAC, rotational intraperitoneal pressurized aerosol chemotherapy.
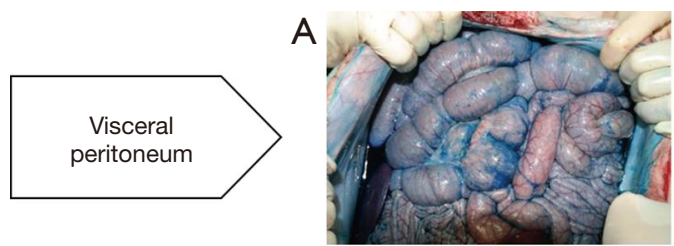

Bowel

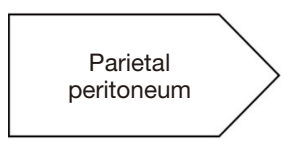

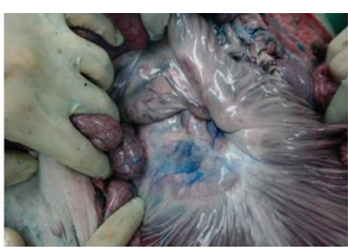

Mesentery

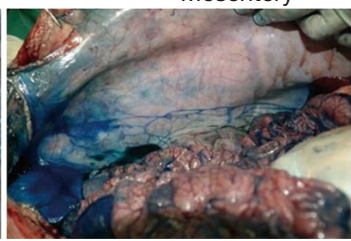

Anterior peritoneum

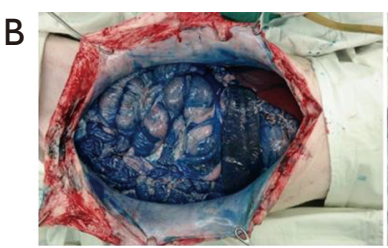

Bowel

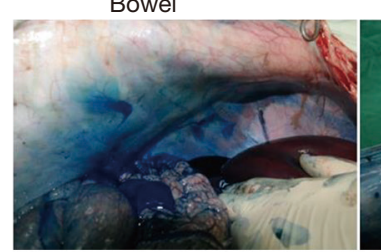

Diaphragmatic peritoneum

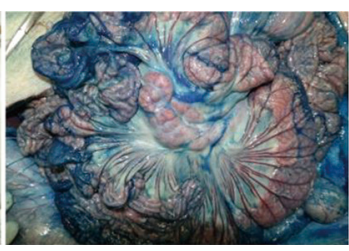

Mesentery

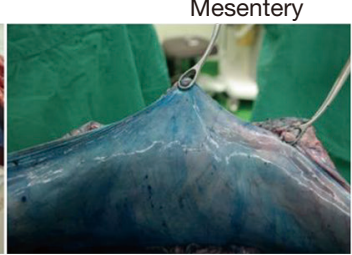

Anterior peritoneum

Figure 3 Comparison of the distribution of drugs by using 1\% methylene blue staining between (A) PIPAC and (B) RIPAC. PIPAC, pressurized intraperitoneal aerosol chemotherapy; RIPAC, rotational intraperitoneal pressurized aerosol chemotherapy.

\section{Operative procedure}

For PIPAC, the nebulizer was inserted into a $12-\mathrm{mm}$ bladeless trocar, and $1 \%$ methylene blue of $150 \mathrm{~mL}$ was nebulized at $30 \mathrm{~mL} / \mathrm{min}$ over a few seconds in the room temperature by the syringe pump which we developed previously $\left(20^{\circ} \mathrm{C}\right)(18)$, and the abdominal pressure was maintained at $12 \mathrm{mmHg}$ for 30 minutes. The aerosol was eliminated using a pressure-limited waste system including filter.

For RIPAC, we developed the conical pendulum motion device, which consists of a DC motor (12V/1.5A, GM35A-3323, Motorbank, Seoul, South Korea), a 3-D printed rotational stick, two end-stops (PCB mounted Endstop switch, RepRap, England) and an Arduino Uno. The nozzle was inserted in a 3-D printed rotational stick, and locked with screw. The angle between the nozzle and the vertical line was determined 30 degrees by calculating the spraying angle of approximately 70 degrees. The rotational stick could not rotate the same direction continually because Teflon tube connected to the syringe pump could be got tangled. Thus, the rotational stick moved repeatedly clockwise and counterclockwise (Figure 2). Thereafter, 1\% methylene blue of $150 \mathrm{~mL}$ was nebulized like PIPAC.

After completion of IP chemotherapy using 1\% methylene blue, we sacrifice the two swine, and compared the distribution of methylene blue throughout the entire abdominal cavity between PIPAC and RIPAC. As a result, RIPAC stained the visceral and parietal peritoneum more strongly than PIPAC (Figure 3). 


\section{Comments}

This experiment confirmed the potential that RIPAC can be superior to PIPAC in terms of the distribution of drugs into the peritoneum in a porcine model. In subsequent experiments, we also confirmed that RIPAC was superior to PIPAC in terms of the penetration depth and tissue concentration of drugs by repetitive experiments in a porcine model (19), which strongly suggests the potential that RIPAC may be more effective than PIPAC for treating PC.

\section{Acknowledgments}

We thank to Soohyun Oh, Eun Ji Lee, Haerin Paik, Se Ik Kim, Hee Su Lee, Junsik Kim, Jung Chan Lee from Seoul National University College of Medicine, and Nara Lee from CHA Gangnam Medical Center. Moreover, we deeply appreciate to Dalim Corp. for the financial support.

Funding: This work was supported by grants from Seoul National University (No. 800-20170249, 800-20180201, 800-20190437) and Seoul National University Hospital (No. 0620173250).

\section{Footnote}

Provenance and Peer Review: This article was commissioned by the Guest Editors (Sang Yoon Park, Jae Weon Kim) for the series "Ultra-Radical Surgery in Ovarian Cancer: Surgical Techniques for Gynecologic Oncologist" published in Gland Surgery. HSK serves as an unpaid editorial board member of Gland Surgery from Aug 2019 to Jul 2021. The article was sent for external peer review organized by the Guest Editors and the editorial office.

Conflicts of Interest: All authors have completed the ICMJE uniform disclosure form (available at http://dx.doi. org/10.21037/gs-2019-ursoc-11). The series "UltraRadical Surgery in Ovarian Cancer: Surgical Techniques for Gynecologic Oncologist" was commissioned by the editorial office without any funding or sponsorship. The authors have no other conflicts of interest to declare.

Ethical Statement: The authors are accountable for all aspects of the work in ensuring that questions related to the accuracy or integrity of any part of the work are appropriately investigated and resolved. This study was approved from the Institutional Animal Care and Use
Committee from Seoul National University Hospital (No. 18-0051-S1A0).

Open Access Statement: This is an Open Access article distributed in accordance with the Creative Commons Attribution-NonCommercial-NoDerivs 4.0 International License (CC BY-NC-ND 4.0), which permits the noncommercial replication and distribution of the article with the strict proviso that no changes or edits are made and the original work is properly cited (including links to both the formal publication through the relevant DOI and the license). See: https://creativecommons.org/licenses/by-nc-nd/4.0/.

\section{References}

1. Heintz AP, Odicino F, Maisonneuve P, et al. Carcinoma of the ovary. FIGO 26th Annual Report on the Results of Treatment in Gynecological Cancer. Int J Gynaecol Obstet 2006;95 Suppl 1:S161-92.

2. Quere P, Facy O, Manfredi S, et al. Epidemiology, management, and survival of peritoneal carcinomatosis from colorectal cancer: a population-based study. Dis Colon Rectum 2015;58:743-52.

3. Robella M, Vaira M, De Simone M. Safety and feasibility of pressurized intraperitoneal aerosol chemotherapy (PIPAC) associated with systemic chemotherapy: an innovative approach to treat peritoneal carcinomatosis. World J Surg Oncol 2016;14:128.

4. Park SJ, Kim J, Kim SN, et al. Practice patterns of surgery for advanced ovarian cancer: analysis from international surveys. Jpn J Clin Oncol 2019;49:137-45.

5. Alberts DS, Liu PY, Hannigan EV, et al. Intraperitoneal cisplatin plus intravenous cyclophosphamide versus intravenous cisplatin plus intravenous cyclophosphamide for stage III ovarian cancer. N Engl J Med 1996;335:1950-5.

6. Armstrong DK, Bundy B, Wenzel L, et al. Intraperitoneal cisplatin and paclitaxel in ovarian cancer. $\mathrm{N}$ Engl J Med 2006;354:34-43.

7. Walker JL, Armstrong DK, Huang HQ, et al. Intraperitoneal catheter outcomes in a phase III trial of intravenous versus intraperitoneal chemotherapy in optimal stage III ovarian and primary peritoneal cancer: a Gynecologic Oncology Group Study. Gynecol Oncol 2006;100:27-32.

8. Knox JD, Mitchel RE, Brown DL. Effects of hyperthermia on microtubule organization and cytolytic activity of murine cytotoxic T lymphocytes. Exp Cell Res 
1991;194:275-83.

9. Steller MA, Egorin MJ, Trimble EL, et al. A pilot phase I trial of continuous hyperthermic peritoneal perfusion with high-dose carboplatin as primary treatment of patients with small-volume residual ovarian cancer. Cancer Chemother Pharmacol 1999;43:106-14.

10. van Driel WJ, Koole SN, Sikorska K, et al. Hyperthermic intraperitoneal chemotherapy in ovarian cancer. N Engl J Med 2018;378:230-40.

11. Tempfer CB, Solass W, Buerkle B, et al. Pressurized intraperitoneal aerosol chemotherapy (PIPAC) with cisplatin and doxorubicin in a woman with pseudomyxoma peritonei: a case report. Gynecol Oncol Rep 2014;10:32-5.

12. Göhler D, Khosrawipour V, Khosrawipour T, et al. Technical description of the microinjection pump (MIPß) and granulometric characterization of the aerosol applied for pressurized intraperitoneal aerosol chemotherapy (PIPAC). Surg Endosc 2017;31:1778-84.

13. Blanco A, Giger-Pabst U, Solass $W$, et al. Renal and hepatic toxicities after pressurized intraperitoneal aerosol chemotherapy (PIPAC). Ann Surg Oncol 2013;20:2311-6.

14. Tempfer CB, Rezniczek GA, Ende P, et al. Pressurized intraperitoneal aerosol chemotherapy with cisplatin and doxorubicin in women with peritoneal carcinomatosis: a

Cite this article as: Mun J, Park SJ, Kim HS. Rotational intraperitoneal pressurized aerosol chemotherapy in a porcine model. Gland Surg 2021;10(3):1271-1275. doi: 10.21037/gs-2019ursoc-11 cohort study. Anticancer Res 2015;35:6723-9.

15. Tempfer CB, Winnekendonk G, Solass W, et al. Pressurized intraperitoneal aerosol chemotherapy in women with recurrent ovarian cancer: a phase 2 study. Gynecol Oncol 2015;137:223-8.

16. Struller F, Horvath P, Solass W, et al. Pressurized intraperitoneal aerosol chemotherapy with low-dose cisplatin and doxorubicin (PIPAC C/D) in patients with gastric cancer and peritoneal metastasis: a phase II study. Ther Adv Med Oncol 2019;11:1758835919846402.

17. Khosrawipour V, Khosrawipour T, Kern AJ, et al. Distribution pattern and penetration depth of doxorubicin after pressurized intraperitoneal aerosol chemotherapy (PIPAC) in a postmortem swine model. J Cancer Res Clin Oncol 2016;142:2275-80.

18. Lee HS, Kim J, Lee EJ, et al. Evaluation of a novel prototype for pressurized intraperitoneal aerosol chemotherapy. Cancers (Basel) 2020;12:633.

19. Lee EJ, Yim GW, Kim HS, et al. Development of rotational injection of pressurized intraperitoneal aeorosl chemotherapy (RIPAC) for treating peritoneal carcinomatosis. Athens: Proceedings of the 21st European Congress of Gynaecological Oncology, 2019:Asbtract No.A-1025-0011-01077. 